\title{
Estilos de aculturación y encrucijadas de la diversidad cultural
}

\section{Antonio Ariño Villarroya}

Universitat de València. Departament de Sociologia i Antropologia Social

Antonio.Arino@uv.es

Recibido: 17-04-2007

Aceptado: 30-09-2008

\section{Resumen}

La diversidad cultural y su gestión política se han convertido en el tema central de nuestro tiempo. Ello está relacionado con el hecho de que en las sociedades de la modernidad avanzada, inmersas en una radicalización e intensificación de los procesos de mundialización, se generan condiciones de pluralismo etnocultural constitutivo (con diversidad de estilos y estrategias de aculturación y nuevas modalidades de conciencia intercultural), que impugnan las pautas de gestión de la diversidad típicas de sociedades precedentes. El artículo aborda los principales estilos de aculturacion imperantes en dicho contexto, con especial referencia a la sociedad española: la pluralidad de estilos vigentes; el predominio de las preferencias a favor de estrategias integradoras; el carácter minoritario del asimilacionismo, y la existencia de una tendencia o evolución histórica de incremento del integracionismo. Finalmente, tras exponer diversos modelos teóricos de gestión política de la diversidad concluye con una apuesta, para estos contextos de pluralismo constitutivo, a favor de los modelos pragmáticos.

Palabras clave: migraciones, asimilacionismo, integracionismo.

\section{Abstract. Acculturation styles and the crossroads of cultural diversity}

Cultural Diversity and its political management has become the central topic of our time. This is related to the fact that in advanced modern societies, submerged in the radicalization and intensification of the processes of globalization, we generate conditions of constituent ethno-cultural pluralism (with a diversity of styles and acculturation strategies and new modalities of intercultural awareness), which challenge the management guidelines of the typical diversities of previous societies.

The article deals with the main acculturation styles that prevail in such contexts, with special reference to Spanish society: The plurality of present styles; the predominance of the preference towards integrating strategies; the minority character of assimilationism; and the existence of a historical increase of integrationism trend or evolution. Finally, after stating various theoretical models of political management of diversity we conclude with a defence of those contexts of constitutive pluralism, in favour of pragmatic models.

Key words: migrations, assimilationism, integrationism. 


\section{Sumario}

1. La creación de una situación de pluralismo etnocultural constitutivo

2. Los estilos de aculturación en la sociedad española
3. La organización de la convivencia en un mundo plural

Bibliografía

Decir que la especie humana se caracteriza por la diversidad de sus manifestaciones culturales constituye una afirmación incontestable que, de tan evidente, resulta banal. Sin embargo, la diversidad cultural y su gestión política se han convertido en el tema central de nuestro tiempo ¿Por qué nos ocupamos y preocupamos por ella? ¿En qué consiste? El lenguaje y los discursos que se elaboran al respecto suelen estar plagados de equívocos y generan tanta confusión como apasionamiento. Pocas veces se distingue entre la diversidad cultural como hecho, como valor, como derecho y como política; $y$, con menor frecuencia aún, se señala en qué puede radicar el carácter inédito de la diversidad cultural en las sociedades de la modernidad avanzada.

En este artículo, sostendremos que, en dichas sociedades, inmersas en una radicalización e intensificación de los procesos de mundialización, se generan condiciones de pluralismo etnocultural constitutivo ${ }^{1}$, que impugnan las pautas de gestión de la diversidad típicas de sociedades precedentes (el asimilacionismo) y promueven una sospecha generalizada de imperialismo latente sobre las proposiciones universalistas. Esta situación de pluralismo etnocultural constitutivo se plasma en una diversidad de estilos y estrategias de aculturación y crea nuevas modalidades de conciencia intercultural, que modifican las condiciones de posibilidad de las políticas de gestión de la diversidad.

De acuerdo con este planteamiento, en la primera parte abordaremos los cambios centrales en los flujos de personas y, muy especialmente, en los flujos migratorios, que producen esta situación de pluralismo constitutivo. Este hecho provoca transformaciones en la conciencia intercultural, es decir, en las preferencias, las actitudes y las creencias que guían los contactos entre grupos diferentes o cuyos contenidos abordan las pautas a seguir en la interacción. Cuatro dinámicas principales cabe esperar: la pluralidad de estrategias y estilos de aculturación; el predominio de las preferencias a favor de estrategias integradoras, tanto entre los grupos que ocupan posiciones dominantes como entre los que no; el carácter minoritario del asimilacionismo, y la existencia de una tendencia o evolución histórica de incremento del integracionismo.

Estas cuatro tendencias han sido analizadas con cierta amplitud en la literatura especializada internacional (Berry, 2006b). Aunque no existen estudios similares en el Estado español, en la segunda parte restringiremos nuestra mirada para efectuar una primera aproximación al análisis de los estilos de aculturación en un contexto de rápido crecimiento de la inmigración, y los obser-

1. Este concepto se inspira en el "pluralismo constitutivo» de que habla Metz (2002). 
varemos a partir de datos de diversas encuestas realizadas en la primera década del siglo XXI en la sociedad española y en la sociedad valenciana. Al menos, esperamos registrar tres impactos fundamentales: el carácter minoritario de las posiciones asimilacionistas, el predominio de las preferencias integradoras y la pluralización de los estilos de aculturación ${ }^{2}$.

Finalmente, retomaremos un vuelo más amplio y, a la luz del debate teórico sobre las políticas de gestión de la diversidad, concluiremos con una apuesta por los modelos pragmáticos para los contextos de pluralismo constitutivo.

\section{La creación de una situción de pluralismo etnocultural constitutivo}

El pluralismo etnocultural constitutivo tiene que ver con la situación en que se encuentran las sociedades contemporáneas, en las que una parte significativa de la población residente es de origen inmigrante y está dispuesta a mantener sus modos de vida y valores en los contextos de inmigración, rechazando de manera radical cualquier forma de asimilación. Por tanto, está directamente relacionado con la generalización e intensificación de los flujos de personas en el horizonte de la globalización, pero no se explica meramente por un cambio en el volumen de dichos flujos.

Inmigrantes ha habido siempre, porque los seres humanos desde antiguo se han desplazado a grandes distancias. Los primeros humanos fueron africanos y el poblamiento de Europa se puede entender como una etapa de la gran colonización de Eurasia, que se produjo, como mínimo, hace 500.000 años. Así pues, la migración es tan antigua como la propia humanidad, y toda la historia de nuestra especie en el planeta es en gran medida la narración de grandes movimientos migratorios, impulsados por razones y causas diversas. $\mathrm{Y}$ todos estos movimientos, de pueblos cazadores, de ejércitos, de esclavos, de perseguidos, de comerciantes, de misioneros, de aventureros, de trabajadores, de turistas, de refugiados, de estudiantes..., colocan ante nosotros una verdad incontestable: los seres humanos tienen pies, no raíces. ¿¿Hay algo nuevo, por tanto, en las migraciones contemporáneas?

En cuatro aspectos me parece que puede sustanciarse la radical novedad de estas migraciones de hoy: la densidad demográfica, la estructuración del mundo en estados naciones, la experiencia postcolonial y las transformaciones en los flujos de signos generadas por las nuevas tecnologías de la información y de la comunicación. De ellos, los dos últimos son especialmente relevantes para la génesis del pluralismo etnocultural constitutivo.

\subsection{La densidad demográfica y la estructuración del mundo en estados naciones}

Las migraciones de hoy son nuevas, de entrada, porque el planeta Tierra ha alcanzado una extraordinaria densidad demográfica y ya no quedan espacios

2. No podemos observar la evolución del integracionismo por carecer de series históricas que permitan efectuar el análisis. Pero allí donde se hallan disponibles, como es el caso de Canadá, Berry muestra una evolución favorable del multiculturalismo y del integracioniso (Berry, 2006a: 37). 
por colonizar. Cuando alguien se mueve, lo hace a un territorio ocupado por más de 6.000 millones de habitantes. En 1800 sólo eran 1.000 millones; en 1927 se habían duplicado, de manera que llegaron a ser más de 2.000 millones. En el tiempo restante hasta hoy, en bastante menos de un siglo, la población mundial se ha multiplicado por tres, y aunque se halle desigualmente repartida por el mapa, ya no existen tierras «vírgenes» (no colonizadas o carentes de propietario) por conquistar y ocupar.

En segundo lugar, el mundo se halla hoy estructurado todo él en estados naciones que actúan como contenedores o recipientes territoriales administrativos de seres humanos y, por tanto, las migraciones internacionales constituyen trasvases de personas entre estos contenedores. No estar incluido en alguno de ellos es ser un apátrida, cuyos sinónimos en el diccionario, son "paria», «vagabundo», «errante». Los derechos de los que las personas son titulares dependen del estado nación y sus leyes. La ciudadanía, esa extraordinaria conquista de la modernidad, tiene una naturaleza restrictiva derivada de su naturaleza e implantación nacional, de manera que no se es ciudadano por el hecho de nacer, por humanidad, sino por la pertenencia a una organización estatal y por territorialidad.

La consolidación y maduración de la estructura del planeta en estados naciones, con sus fronteras y soberanía, con sus pasaportes, visados, permisos, licencias, estatutos, marcos institucionales, etc., es un fenómeno muy reciente, pero universal; en realidad, constituye una de las primeras dimensiones de la globalización, ya que consiste en la difusión general de un modelo de organización política por todo el planeta y la creación de aparatos burocráticos e institucionales de vigilancia de fronteras, que ahora se delimitan y se controlan con notable precisión.

¿Por qué el estado nación es tan importante en este asunto? Porque de él depende el alcance y la extensión de los derechos de ciudadanía y, por lo tanto, el grado y el tipo de integración o exclusión de los inmigrantes, es decir, de los no nacionales; y porque necesariamente desarrolla una ideología, supraétnica pero territorial, con pretensiones de universalidad, autenticidad y pureza, que trata de inculcar mediante el sistema educativo. Éste es el encargado de transformar a los individuos en ciudadanos y de crear en ellos el sentido de una conciencia de destino. Por tanto, hay un currículo oculto en el sistema escolar de carácter nacionalista y estatalista, así como una lógica de tipo asimilacionista que se impone a la diversidad.

Un efecto más debe señalarse, por lo menos, derivado de la estructuración del mundo en estados naciones: mediante este proceso, se crea un sistema mundial de relaciones internacionales, moderado por Naciones Unidas y por su complejo de organismos (como, por ejemplo, UNESCO), que, al menos en el plano formal de la acción diplomática y en el plano normativo del derecho, sitúa a todos los estados naciones en un plano de igualdad, con la consiguiente erosión discursiva de las relaciones de superioridad. Esta equiparación de los actores nacional-estatales se ha hecho especialmente visible a partir del triunfo de los procesos de liberación y descolonización. 


\subsection{Los procesos de liberación colonial}

En tercer lugar, el mundo actual es resultado de los procesos de liberación colonial posteriores a la Segunda Guerra Mundial. Este hecho tiene consecuencias muy importantes para los procesos migratorios. Como ha señalado Wallerstein (2008), a partir de 1945, el orientalismo, que fue la ideología legitimadora del colonialismo, al postular la existencia de un factor de inferioridad esencial en los «pueblos orientales» que obstaculizaba su acceso a la modernidad, quedó desenmascarado e invalidado. Y con la irrupción en la escena mundial de los nuevos pueblos naciones liberados, también sus comunidades inmigrantes pudieron identificarse, sin complejos y con orgullo, con las naciones de procedencia, y desafiar, en nombre del sufrimiento histórico infligido por las potencias imperialistas, el esquema occidental de valores. El resultado fue el cuestionamiento sistemático de la superioridad occidental, del universalismo europeo y de las políticas correlativas de asimilación.

Por ello, ahora, ser persa en París no sólo no requiere una justificación particular, sino que puede consistir en una forma proactiva de pertenecer a la nación persa; residir en Heidelberg siendo kurdo, no constituye un impedimento para afirmar la lealtad a la nación kurda, y ser sij en Londres tampoco conlleva obstáculo alguno para la pertenencia activa a la comunidad sij. En cualquier lugar y circunstancia, la patria y el orgullo étnico pueden estar presentes y desarrollarse. Más todavía, esa situación de diáspora aviva y alimenta dichos sentimientos e identidades.

Aquí se encuentra uno de los cimientos más sólidos del pluralismo constitutivo, porque no sólo los pueblos liberados y sus comunidades diáspóricas, sino también amplias capas de la población occidental, críticas con el eurocentrismo y el occidentalismo, sostienen que el universalismo de los derechos, del progreso y de la modernidad, incluso de la ciencia, no es sino un particularismo, espacial y temporalmente determinado. Y, por tanto, que las relaciones entre lo universal y lo particular han de replantearse y reconstruirse a partir del reconocimiento de una nueva generación de derechos: los culturales.

\subsection{El impacto de la globalización y de los flujos de signos}

Pero el factor que, de manera más radical e imprevista, ha contribuido a crear las condiciones para el desarrollo de las comunidades diaspóricas y la instalación del pluralismo etnocultural con carácter constitutivo, se halla en las transformaciones de los flujos de signos, producidas por las innovaciones en los sistemas de información y comunicación y la incidencia de las redes computacionales como redes sociales ${ }^{3}$.

3. La globalización, de hecho, puede ser entendida como un incremento históricamente cualitativo en los flujos de signos, objetos, sustancias y personas. Es históricamente cualitativo porque afecta a su extensión, a su intensidad, a su diversidad, a su velocidad y a su impacto. A su extensión, en tanto que alcanza a todo el planeta; a su intensidad, en cuanto se ha 
Y eso es posible ahora porque, gracias a la comunicación instantánea que procuran los nuevos medios de comunicación, los acontecimientos de Kurdistán, de la India, de Palestina, de Marruecos, de Senegal, de Ecuador y Bolivia se encuentran accesibles en las diversas ventanas abiertas al mundo que cada uno tiene instaladas en su casa o en el locutorio; y gracias a las herramientas de la comunicación móvil, se pueden mantener activas las interacciones sociales previas o incluso construir otras nuevas de mayor alcance. Nadie, si lo pretende, está alejado de su cultura originaria, porque las nuevas tecnologías de la comunicación han desbordado las distancias físicas, han quebrado la relación que existía entre el tiempo y el espacio, y, separados por miles de kilómetros, se pueden seguir de cerca, con vívidas imágenes, los ritos de los centros y líderes religiosos propios y los acontecimientos más descollantes que afectan a los compatriotas.

El modelo nacional-estatal estipulaba, en principio, que los ciudadanos de una nación enfocaban toda su vida en la comunidad nacional y que ésta era inmutable. Para quienes venían de fuera se preveían procesos de asimilación y de «naturalización». Pero, hoy, tanto la movilidad de la mano de obra, como las características del mundo postcolonial y la instantaneidad de las comunicaciones, ponen en cuestión dicha lógica. Las fronteras se han desplazado, no están en los Pirineos o en el Estrecho, sino en cada patio de vecinos, en cada barrio, en cada escuela, en la interacción cotidiana, en el color de los cuerpos, y, a su vez, los lazos, las interacciones y las lealtades a distancia constituyen la nueva urdimbre del ecosistema comunicacional postmoderno. No hay ningún lugar del planeta que no se vea afectado ya y transformado por los flujos globales, y ésta es la causa de que, al tornarse porosas las fronteras físicas, cobren mayor relevancia las diferencias culturales.

La globalización y, muy especialmente, las transformaciones en los flujos de signos modifican la naturaleza y el significado de las migraciones contemporáneas. Ello se hace especialmente visible, según Cristina Blanco, en dos factores que, a mi entender, no son sino las dos caras de la misma moneda: el incremento de las actividades trasnacionales y la configuración de enclaves étnicos.

El énfasis en el transnacionalismo permite hacer visible la creciente intensidad y extensión de los flujos circulares de personas, información, bienes y símbolos alcanzados por las migraciones internacionales (Blanco, 2008: 269). Aunque no todos los migrantes puedan ser considerados transnacionales - de hecho, sólo lo serían aquéllos que mantienen relaciones estrechas entre origen y destino, con una acusada bipolarización vital—, la transnacionalidad constituye la tendencia emergente y hegemónica del tiempo actual. Por otro

producido un salto cualitativo en el volumen de flujos; a su velocidad, dado el carácter instantáneo de los mismos y la ruptura de la relación histórica entre espacio y tiempo; a su impacto, porque crea una conectividad o una interdependencia compleja entre todos los lugares del planeta, de manera que lo local deja de gozar de la configuración que tuvo históricamente (Held y otros, 1999). 
Tabla 1. El uso de las NTIC en España en función de la nacionalidad

\begin{tabular}{lcccccc}
\hline & Total & $\begin{array}{l}\text { Personas que } \\
\text { usan teléfono } \\
\text { personas }\end{array}$ & $\begin{array}{l}\text { Personas que } \\
\text { han utilizado } \\
\text { alguna vez } \\
\text { el ordenador }\end{array}$ & $\begin{array}{l}\text { Personas que } \\
\text { han utilizado } \\
\text { alguna vez } \\
\text { Internet }\end{array}$ & $\begin{array}{l}\text { Personas que } \\
\text { han comprado } \\
\text { alguna vez a } \\
\text { través de Internet }\end{array}$ & $\begin{array}{l}\text { Personas que } \\
\text { disponen de } \\
\text { dirección de correo } \\
\text { electrónico privada }\end{array}$ \\
\hline $\begin{array}{l}\text { Total personas } \\
\text { Nacionalidad: }\end{array}$ & 33.571 .031 & 84,9 & 60,9 & 53,8 & 19,6 & 38,9 \\
$\begin{array}{c}\text { española } \\
\text { Nacionalidad: } \\
\text { extranjera }\end{array}$ & 31.667 .145 & 84,4 & 60,7 & 53,5 & 19,7 & 38,9 \\
\hline
\end{tabular}

Fuente: Encuesta sobre equipamiento y uso de tecnologías de la información y comunicación en los hogares, segundo semestre de 2007 (INE, 2007).

lado, las nuevas herramientas sociales de la comunicación permiten la creación y el mantenimiento de comunidades imaginadas de larga distancia.

Los datos sobre los usos de las NTIC y de las herramientas sociales digitales por parte de los inmigrantes son concluyentes. De hecho, constituyen una fuente privilegiada de negocio para las compañías de comunicación móvil. Una ojeada rápida a los usos de las NTIC en España, según los datos de la Encuesta de equipamiento y uso de tecnologias de la informacion y de la comunicación en los hogares en el segundo semestre de 2007 arroja resultados significativos.

Según los datos ofrecidos en la tabla, se observa que el porcentaje de personas de nacionalidad extranjera que usan el móvil, el ordenador, Internet o el correo electrónico supera a las personas de nacionalidad española. Solamente en un punto se produce la situación inversa, que es cuando se trata de la utilización de Internet para la realización de compras. Por tanto, resulta patente la incorporación de estos instrumentos como herramientas comunicativas básicas y medios ordinarios de interacción a distancia por parte de los inmigrantes.

Las NTIC potencian extraordinariamente las actividades transnacionales, las maneras de relacionarse con las sociedades de origen, de construir las identidades, etc., como también de relacionarse con las sociedades de destino (distanciarse). Y es la intensidad de estas relaciones transnacionales y su instantaneidad las que permiten a los inmigrantes organizarse como comunidades culturales diferenciadas en los lugares de destino e invalidan cualquier estrategia o política de asimilación.

Por ello, sostengo que otra faceta de los modernos procesos migratorios, relacionada con la transnacionalización, se halla en la creación de enclaves etnoculturales. Para Blanco, los cambios estructurales de los flujos migratorios a escala mundial transforman los estados naciones en mosaicos étnicos y culturales, lo cual genera importantes desafíos a la integración y a la cohesión social, y produce un nuevo tipo de estratificación, la étnica. En este sentido, la concentración residencial de grupos inmigrantes se ha interpretado generalmente como resultado de los procesos de exclusión social y étnica, genera- 
dora de pérdida de oportunidades para los residentes, al cerrarles en un espacio de relaciones segregadas y obstaculizar el contacto con la sociedad receptora.

Ésa es una perspectiva que no se puede abandonar ni minusvalorar, ya que forma parte de la realidad estructural y de las condiciones de vida de las poblaciones inmigrantes. Pero no excluye otras interpretaciones alternativas o complementarias y, sobre todo, no capta la naturaleza novedosa de las migraciones creada por los medios de comunicación móvil: las concentraciones de inmigrantes también se pueden entender hoy como asentamientos, relativamente voluntarios y por tanto estratégicos, que tratan de proveer a sus miembros de un sentido de comunidad y de una vivencia consistente de la propia cultura. Así, los enclaves étnicos constituyen pequeñas comunidades de inmigrantes insertadas en las sociedades de destino que proporcionan a sus miembros un espacio de sociabilidad, identidad y lealtad cultural, con lo cual suman un doble efecto: de estructura (segregación) y de elección (comunidad). Estos grupos, a su vez, se hallan conectados mediante redes asociativas transnacionales a sus países de origen y a organizaciones internacionales específicas.

En el mundo globalizado por la intensidad de los flujos de personas, los flujos de signos actúan en múltiples direcciones: ponen en contacto a grupos culturalmente diferentes (lo que, en cierto sentido, genera inevitablemente efectos de homogeneización cultural instrumental, que aquí no se han tratado); permiten la creación de comunidades diaspóricas que mantienen y refuerzan sus lazos, identidades y lealtades nacionales preexistentes (con la consiguiente recreación de grupos étnicos en enclaves etnoculturales); conectan estos grupos no sólo con sus naciones de origen, sino también con otras comunidades diaspóricas o con miembros de ellas por todo el mundo (lo que supone la invención de un nuevo tipo de comunidades imaginadas de alcance global). En estas condiciones, en la interacción entre autóctonos y migrantes, quedan invalidadas las relaciones de superioridad cultural y las políticas asimilacionistas, y se desafía el discurso y la ideología universalista.

Un contexto como éste, que he calificado de pluralismo constitutivo etnocultural, debe caracterizarse a un tiempo por una pluralidad de estilos de aculturación en la conciencia social y por un carácter minoritario de las posiciones asimilacionistas. Esto es lo que trataremos de mostrar en el apartado siguiente.

\section{Los estilos de aculturación en la sociedad española}

A continuación, estudiaremos la incidencia de un contexto de pluralismo etnocultural constitutivo, como el que producen los contemporáneos flujos migratorios y los flujos simbólicos, sobre las preferencias y los estilos de aculturación de la población. Tras presentar el significado que tienen para nosotros los conceptos fundamentales, ofreceremos los resultados que pueden extraerse sobre este asunto a partir de encuestas realizadas en la sociedad española. Utilizaremos principalmente los datos de un barómetro del CIS de noviem- 
bre de 2005, porque las preguntas introducidas en el cuestionario permiten una primera aproximación, y la completaremos después con los datos de una encuesta realizada en 2002 a la población valenciana, en el marco de un proyecto más amplio sobre la situación de la inmigración en la Comunidad Valenciana.

\subsection{Estrategias y estilos de aculturación}

El término aculturación tiene una larga historia en las ciencias sociales y, como suele suceder, se ha utilizado con distintos significados (Sam, 2006: 11-26). La definición que goza de mayor consenso fue plasmada en un conocido memorándum por los antropólogos Redfield, Linton y Herskovits, en 1936. Para ellos, la aculturación es «ese fenómeno que se produce cuando grupos de individuos que pertenecen a distintas culturas participan en contactos directos, con los consiguientes cambios en las pautas culturales originales de ambos grupos» (Redfield y otros, 1936). Así pues, la aculturación conlleva contactos, influencias recíprocas, aunque sean de un alcance muy distinto en cada uno de los grupos e individuos, y cambios en ambos grupos y en sus miembros.

Para Berry, uno de los científicos sociales que más ha contribuido a estudiar los procesos de aculturación en las sociedades plurales contemporáneas, el proceso de aculturación se puede estudiar tanto en el nivel individual como en el de los grupos y la sociedad general. Depende o consta de dos dimensiones: del grado en que los individuos participan en la vida cultural de la nueva sociedad (participación) y, simultáneamente, del grado en que mantienen su identidad cultural original (fidelidad). Al conjugar estas dos dimensiones (orientación hacia el propio grupo y preferencia por la continuidad cultural, de un lado, y orientación al contacto con otros grupos y participación en sus pautas culturales, de otro), se obtienen cuatro estrategias para las relaciones interculturales: integración, asimilación, separación y marginalización.

Desde el punto de vista de los grupos etnoculturales no dominantes, cuando los individuos no desean mantener su identidad cultural y se implican en la interacción cotidiana con las otras culturas, nos hallamos ante una estrategia de asimilación; si los individuos evitan los contactos con otros grupos y defienden su identidad, estaremos ante estrategias de separación; si se valoran simultáneamente la participación en otras culturas y el mantenimiento de las pautas propias, entonces se producen estrategias de integración; finalmente, cuando no se da un interés ni en el mantenimiento de las pautas propias ni en la interacción con las de otros grupos, se produce la marginalización.

El estudio de las estrategias de aculturación, así entendidas, es complejo. Se trata de analizar preferencias, discursos y prácticas; de diferenciar entre los grupos dominantes y los no dominantes; entre el nivel individual, el grupal y el institucional; de tener en cuenta los contextos económicos, sociales y políticos en que se dan los contactos; de tomar en consideración los tipos de grupos en función de variables como la duración del contacto (permanente o temporal), el carácter voluntario o forzado del mismo y si los grupos son sedentarios 
o migrantes; de analizar otros factores, como el tamaño de los grupos, sus recursos, su poder y sus derechos, y, sobre todo, de estudiar cuidadosamente distintas dimensiones específicamente culturales como pautas de diversidad, igualdad de trato, conformidad, capital económico, relaciones con el espacio y con el tiempo, y variaciones en la lengua y en la religión.

Nuestro planteamiento aquí es forzosamente menos ambicioso. Nos proponemos efectuar una primera incursión en este territorio, no mediante una investigación diseñada ad hoc, sino observando las potencialidades que para ello ofrecen las bases de datos públicas. Por eso mismo, no estudiaremos las estrategias que se ponen en juego en las relaciones interculturales, sino una dimensión más abstracta, lo que hemos denominado estilos de aculturación, entendiendo por tales los tipos de preferencias relativos a las orientaciones que guían las opiniones y las conductas de la población en los asuntos concernientes a la diversidad cultural. La gente tiene distintas opiniones y puntos de vista sobre la existencia de la pluralidad cultural y sobre los contactos entre los individuos y los grupos. Las opiniones sobre dos cuestiones son especialmente relevantes para nuestro propósito: se deben establecer o no contactos e intercambios con otras culturas; se debe mantener y proteger o no la propia identidad cultural.

\subsection{Perspectivas sobre la diversidad cultural en la sociedad española}

Comenzaremos con los datos procedentes del barómetro del CIS de $2005^{4}$. En esta encuesta, la inmigración aparece, después del paro, como el segundo problema que más preocupa a los españoles: un $38 \%$ lo cita como preocupante. En dicha toma de posición, se anticipan otras de índole similar. Así, cuando se pregunta a los entrevistados si el número de personas de otros países que residen en España les parecen «demasiadas», «bastantes, pero no demasiadas» o "pocas», la mayoría, un 60\%, contesta que son demasiadas. En la misma dirección, la inmensa mayoría se manifiesta partidaria de que se pongan restricciones de entrada fundadas en las necesidades laborales: el $85 \%$ sostiene que sólo se debe permitir ingresar en el país a quienes vengan con un contrato de trabajo. Por tanto, las elevadas frecuencias obtenidas por estas categorías de respuesta muestran la existencia de una preocupación creciente y de una concepción restrictiva e instrumental de los flujos migratorios.

Sin embargo, incluso en estas circunstancias, se sostiene también que quienes han venido a vivir aquí deberían tener y disfrutar de los mismos derechos que los demás (las posiciones de acuerdo con esta afirmación llegan al 79\%),

4. Ficha técnica del estudio número 2.625, correspondiente al barómetro de noviembre de 2005. Ámbito: nacional; universo: población española de ambos sexos mayor de dieciocho años y más; tamaño real: 2.485 entrevistas. Para un nivel de confianza del 95,5\% (dos sigmas), y $\mathrm{P}=\mathrm{Q}$, el error real es de $\pm 2,0 \%$ para el conjunto de la muestra y en el supuesto de muestreo aleatorio simple. Para un estudio sobre este barómero, ver Aierdi y Vidal de Rada, 2008. 
Tabla 2. Criterios a tener en cuenta para regular los flujos migratorios

\begin{tabular}{lcc}
\hline Aspectos a tener en cuenta a la hora de aceptar que una persona venga aquí & Media & $(N)$ \\
\hline Que tenga un buen nivel educativo & 5,62 & $(2351)$ \\
Que tenga familiares cercanos viviendo aquí & 4,74 & $(2338)$ \\
Que hable castellano o la lengua oficial de esta comunidad autónoma & 5,22 & $(2382)$ \\
Que sea de un país de tradición cristiana & 2,98 & $(2322)$ \\
Que sea de raza blanca & 1,72 & $(2375)$ \\
Que tenga mucho dinero & 1,80 & $(2337)$ \\
Que tenga una cualificación laboral de las que España necesita & 6,40 & $(2363)$ \\
\hline
\end{tabular}

Fuente: Banco de datos del CIS, Estudio 2625, barómetro de noviembre de 2005.

Nota: En la escala, 0 significa nada importante y 10, muy importante.

y ni la afinidad cultural ni la asimilación aparecen como criterios determinantes para regular los flujos. Así, cuando se propone a los entrevistados que valoren las tomas de posición sobre los aspectos a considerar para establecer la política de flujos, ni la afinidad religiosa («que sea de un país de tradición cristiana»), ni la étnica ("que sea de raza blanca») aparecen como factores determinantes. Esto es lo que se observa en la tabla 2, donde se ofrecen las medias obtenidas en una escala que va de 0 a 10 para una pregunta que solicita la valoración de diversos aspectos relacionados con la regulación de las migraciones.

Pero en el cuestionario se contienen otras dos preguntas que todavía son más relevantes para el análisis de las posiciones en torno a la diversidad cultural derivada de los flujos migratorios. En la primera de ellas, se presentan cuatro afirmaciones (ver tabla 3) y se pide a los entrevistados que muestren su acuerdo o su desacuerdo con ellas.

Las respuestas obtenidas esbozan las complejidades de la conciencia intercultural: de un lado, aparece una cierta predilección por una homogeneidad cultural básica o por una especie de cultura común de fondo (la afirmación "para un país, es mejor que todo el mundo comparta las mismas costumbres y tradiciones» logra el acuerdo del 59\% de los entrevistados ${ }^{6}$ ), pero también queda claro que, en dicha homogeneidad, no tiene cabida la uniformidad religiosa, pues la afirmación correspondiente («para un país, es mejor que en él convivan gentes de distintas religiones») obtiene el porcentaje más elevado de respuestas en las posiciones acordes con el pluralismo religioso: un 40\%.

De otro lado, la mayoría se muestra contraria al separacionismo educativo y, por ello, un $57 \%$ está en desacuerdo con que «las distintas comunidades

5. Conviene tener presente que el $80 \%$ se declara católico en la encuesta.

6. De acuerdo con el estudio de Aierdi y Vidal de Rada (2008), se trata de una opinión que varía claramente con la ideología, con el capital educativo y con la pertenencia de clase (la homogeneidad encuentra sus apoyos fundamentalmente en las posiciones de derecha, en los niveles educativos más bajos y entre la clase trabajadora). 
Tabla 3. Grado de acuerdo con afirmaciones sobre pautas culturales de la población inmigrante

$\begin{array}{lll}\text { De acuerdo } & \begin{array}{l}\text { Ni acuerdo } \\ \text { ni desacuerdo }\end{array} & \begin{array}{l}\text { En } \\ \text { desacuerdo }\end{array}\end{array}$

Para un país, es mejor que casi todo el mundo comparta las mismas costumbres y tradiciones 58,9 10,6 26,7

Para un país, es mejor que en él convivan gentes de distintas religiones

39,6

22,3

29,2

Las distintas comunidades de personas

que han venido a vivir a España

deberían poder educar a sus hijos

en escuelas separadas, si así lo desean 26,2 8,9 56,8

Si un país quiere evitar problemas, debe poner fin a la inmigración 24,7 13,0 53,9

Fuente: Banco de datos del CIS, Estudio 2625, barómetro de noviembre de 2005.

de personas que han venido a vivir a España deberían poder educar a sus hijos en escuelas separadas, si así lo desean», pero también una mayoría, el 54\%, está en desacuerdo con el cierre o el encastillamiento nacional de los autóctonos («si un país quiere evitar problemas, debe poner fin a la inmigración»).

La segunda de las preguntas del cuestionario que interesa abordar en este contexto plantea a la población entrevistada qué opina en relación con la diferencia cultural. Dado que, a menudo, los inmigrantes residentes en España tienen costumbres, lengua y cultura diferentes de las españolas, se ofrecen a los entrevistados dos sentencias, para que manifiesten con cuál de ellas se sienten más identificados. Las frases rezan así:

- "Aunque se queden a vivir en España y aprendan muestra lengua y nuestras costumbres, es bueno que los inmigrantes mantengan también su lengua y sus costumbres.»

- «Si los inmigrantes desean permanecer en España, deben olvidar sus costumbres, aprender el idioma y aceptar las costumbres españolas.»

El primer aspecto a destacar, al observar los resultados registrados, es que los encuestados aceptan el reto de la entrevista y no se refugian en la comodidad del no sabe / no contesta, pues sólo un $6 \%$ adopta dicha opción. En cambio, un $72 \%$ se manifiesta conforme con la primera sentencia, es decir, con la afirmación que considera bueno que las comunidades inmigrantes mantengan su identidad cultural propia, y solamente un $22 \%$ se coloca del lado de la asimilación.

Así pues, los datos de este interesante barómetro del CIS ofrecen información relevante sobre las posiciones de la población española ante la inmigración en general y muy específicamente ante la realidad de la diversidad cul- 
Tabla 4. Grado de acuerdo con que la llegada de los inmigrantes es enriquecedora para la cultura de España

\begin{tabular}{lc}
\hline & España \\
\hline Muy de acuerdo & 8,3 \\
De acuerdo & 36,7 \\
Ni de acuerdo ni en desacuerdo & 13,1 \\
En desacuerdo & 24,1 \\
Muy en desacuerdo & 10,3 \\
NS/NC & 7,6 \\
\hline$(N)$ & $(3191)$ \\
\hline
\end{tabular}

Fuente: CIS, encuesta no 2.667/0, La identidad nacional en España.

tural. De un lado, se constata el carácter minoritario de posiciones como el asimilacionismo y el separacionismo; de otro, también resulta evidente la complejidad y ciertas ambigüedades de la conciencia intercultural, es decir, de la conciencia relativa a las relaciones entre individuos y grupos de culturas diferentes. Pero el dato más destacable es el referido a la predominancia de una visión positiva de la inmigración.

Todo ello queda rubricado por los resultados que arroja una pregunta de una encuesta específica sobre el espinoso y escurridizo asunto de la identidad nacional, realizada por el CIS en $2007^{7}$. En ella, una de las preguntas solicita a los entrevistados que tomen posición sobre varias afirmaciones referidas a los inmigrantes. Es de interés para nuestro propósito la que propone una valoración positiva de la inmigración, y reza así: «la llegada de inmigrantes enriquece la cultura de España». Los resultados obtenidos se ofrecen en la tabla 4.

Si sumamos las frecuencias de quienes manifiestan estar muy de acuerdo y de acuerdo, se obtiene un $45 \%$. En cuanto a la suma de los desacuerdos, es claramente inferior: un 34,4\%. Un 13,1\% se muestra indiferente y un 7,6\% no sabe / no contesta. Estos resultados son importantes, tanto por el contexto en el que se obtienen — una encuesta sobre la identidad nacional en España-, como por la claridad y la rotundidad con que se plantea la pregunta. Los resultados son inferiores a los obtenidos en otras circunstancias, pero el carácter mayoritario de la posición favorable a una valoración positiva de la aportación cultural de la población inmigrante es inequívoco.

Los resultados parecen, pues, concluyentes, pero el contenido de estas encuestas del CIS, como el de la inmensa mayoría de las que se han realizado en España, no permite una identificación más clara y una exploración más sistemática de los estilos de aculturación presentes en la sociedad española. 
Tabla 5. Acuerdo o desacuerdo con afirmaciones sobre pautas de la población inmigrante en la Comunidad Valenciana

Están de acuerdo con las siguientes afirmaciones* Comunidad Valenciana

Aunque se queden a vivir en la Comunidad Valenciana y aprendan nuestra lengua y nuestras costumbres, es bueno que los inmigrantes mantengan también su lengua y sus costumbres 66,6

Si los inmigrantes quieren permanecer en la Comunidad Valenciana, deben olvidar sus costumbres, aprender nuestra lengua y aceptar nuestras costumbres

$\mathrm{NS} / \mathrm{NC}$

Total 100

* P. 28: «A menudo, los inmigrantes que viven en la Comunidad Valenciana tienen una cultura, una lengua y unas costumbres distintas a las nuestras. Con respecto a esto, dígame, por favor, con cuál de las siguientes afirmaciones está usted más de acuerdo».

Fuente: Ariño, A. (dir.), La inmigración en la Comunidad Valenciana. Informe para la Generalitat Valenciana.

\subsection{Los estilos de aculturación en la población valenciana}

Para acotar mejor los estilos de aculturación, que emergen en un contexto de rápido crecimiento del volumen de población inmigrante, acudiremos a una encuesta realizada en la Comunidad Valenciana en $2002^{8}$. En el cuestionario, se introdujeron dos preguntas para estudiar los estilos actitudinales en relación con los procesos de aculturación que pone en marcha la nueva situación de los flujos migratorios y los enclaves etnoculturales. En primer lugar, examinaremos las respuestas a cada una de ellas por separado; después, efectuaremos un cruce de ambas, con el fin de determinar los estilos subyacentes.

La primera pregunta planteaba a los entrevistados que expresaran su grado de acuerdo con dos afirmaciones similares a las que hemos visto en la encuesta del CIS de 2005: una define posiciones de carácter asimilacionista y la otra posiciones más integracionistas y multiculturales. Los resultados, que se ofrecen en la tabla 5, siguen la misma pauta que los obtenidos para la sociedad española.

En concreto, un $67 \%$ de la población valenciana encuestada defiende una actitud de convivencia multicultural sobre una base de integración instru-

8. La encuesta formaba parte de un estudio encargado a la Universitat de València por la Generalitat Valenciana y que llevaba por título La inmigración en la Comunidad Valenciana: Situación actual y paradigmas politicos de integración. La explotación de los datos de la encuesta fue realizada por A. Ariño, Rafael Castelló y Ramón Llopis. Ficha técnica: el universo estaba constituido por la poblacion empadronada en la Comunidad Valenciana de dieciocho y más años; se realizaron 1.809 entrevistas en el domicilio de los entrevistados, del 14 de octubre al 8 de noviembre de 2002. Error muestral: $\pm 2,36$, con un nivel de confianza del $95,5 \%$, y $p=q=50 \%(2 \sigma)$. 
mental, lo que significa que acepta como valioso que las comunidades de inmigrantes mantengan sus diferencias culturales, mientras que un $28 \%$ adopta un estilo asimilacionista y, pese al equilibrio que ofrece la primera sentencia, defiende explícitamente que los inmigrantes «deben olvidar» sus costumbres y adoptar las de la sociedad receptora. El porcentaje de los que no saben o no contestan se sitúa en un $5 \%$.

La segunda pregunta cambia la perspectiva e interpela a los entrevistados no sobre cómo han de comportarse los inmigrantes en el contexto de la migración y el contacto intercultural, sino por cómo han de hacerlo los autóctonos: defender su identidad cultural o beneficiarse del contacto con las personas de otras culturas. En concreto, se presentan dos afirmaciones y se pide que los entrevistados manifiesten si están de acuerdo o en desacuerdo con cada una de ellas. La primera aserción propone que "para las personas de mi cultura, es enriquecedor relacionarse con grupos de personas de otras culturas", mientras que la segunda afirma "considero valioso defender ante todo el mantenimiento de mi identidad cultural y sus rasgos característicos». Las respuestas obtenidas se reflejan en la tabla 6 .

El 65\% se manifiesta acorde con la primera afirmación: para las personas de mi cultura, es enriquecedor relacionarse con grupos de personas de otras culturas; en cambio, un $22 \%$ se manifiesta en desacuerdo con ella y, por tanto, rechaza como valioso el contacto intercultural, y un $13 \%$ se sitúa en el territorio, más o menos neutro, de la indefinición.

En las pautas obtenidas por la segunda afirmación, se dan variaciones significativas. Así, la frecuencia de acuerdo que obtiene es sensiblemente superior que en la primera, ya que es apoyada por un $85 \%$, es decir, 20 puntos porcentuales más de apoyo; el desacuerdo se da en un $10 \%$ de los casos y el no sabe / no contesta se mantiene en unos niveles más reducidos. Al parecer, la

Tabla 6. Porcentajes de acuerdo o desacuerdo con afirmaciones relativas a la diversidad cultural en la Comunidad Valenciana

$\%$

Afirmaciones*

Acuerdo Desacuerdo

NS/NC

Para las personas de mi cultura, es enriquecedor relacionarse con grupos

de personas de otras culturas $64,7 \quad 21,8$

Considero valioso defender ante todo el mantenimiento de mi identidad cultural y sus rasgos característicos 84,7 9,8 5,4

* P. 29: «En torno a la cultura de las sociedades, se suelen mantener algunas opiniones diversas. Le voy a leer dos frases para que Ud. me diga en qué medida está o no de acuerdo con cada una de ellas».

Fuente: Ariño, A. (dir.), La inmigración en la Comunidad Valenciana. Informe para la Generalitat Valenciana. 


\begin{tabular}{|l|c|l|l|}
\hline \multicolumn{4}{|c|}{ Modelos y estilos de aculturación } \\
\hline \multicolumn{2}{|c|}{} & \multicolumn{2}{|l|}{$\begin{array}{l}\text { Los inmigrantes han de mantener su lengua } \\
\text { y sus costumbres, aunque aprendan las nuestras }\end{array}$} \\
\cline { 2 - 4 } & \multicolumn{2}{|c|}{ Mantener } & \multicolumn{1}{c|}{ Olvidar } \\
\hline $\begin{array}{l}\text { Las relaciones con } \\
\text { grupos de cultura } \\
\text { diferente enriquece } \\
\text { la mía }\end{array}$ & Sí & Integración & Asimilación \\
\cline { 2 - 4 } & No & Separación & Deculturación \\
\hline
\end{tabular}

Cuadro 1.

situación de contacto intercultural motiva una reafirmación de la identidad de la población autóctona.

Una vez que hemos presentado las distribuciones y las dispersiones de respuesta de cada una de las frases relativas a las actitudes identitarias en su relación con el contacto con otras culturas, nos inspiramos en el modelo de Berry ${ }^{9}$ para el análisis de los estilos de aculturación, con algunas ligeras modificaciones. La razón para ello es doble, tanto técnica como histórica. Por una parte, la posición respecto al mantenimiento de la propia identidad ofrece bastante menos varianza que la posición respecto al mantenimiento de la lengua y las costumbres de los inmigrantes. Y, por otra parte, en la sociedad española la inmigración es un fenómeno todavía muy reciente.

En estas condiciones, hemos creído más conveniente cruzar un indicador de posición con respecto a la propia identidad de la población autóctona con otro que se refiere a la identidad de los inmigrantes. De un lado, se encuentra la afirmación «aunque se queden a vivir en la Comunidad Valenciana y aprendan nuestra lengua y costumbres, es bueno que los inmigrantes mantengan también su lengua y sus costumbres» que permite dos opciones: los entrevistados piensan que los inmigrantes han de mantener su propia cultura o consideran que han de olvidarla. De otro lado, tomamos la proposición "para las personas de mi cultura, es enriquecedor relacionarse con grupos de personas de otras culturas», que también admite dos alternativas: las relaciones con otra cultura sí son enriquecedoras para la mía o dichas relaciones no son enriquecedoras.

Como consecuencia del cruce, resultan cuatro estilos de aculturación, que se recogen en el cuadro 1 .

9. Ver, en R. G. TONKS y Anand C PARANJPE, Two sides of acculturation: Attitudes toward multiculturalism and national identity amongst immigrant and canadian born youth. Comunicación presentada en la Third National Metropolis Conference, 15 de enero de 1999, Simon Fraser University Harbour Centre, Vancouver, B. C.; Randal G. TONKS y Anand C. PARAnjPE, Identity, youth and immigration: Narratives of acculturation and adjustment, en http://ceris.metropolis.netlevents/4metpres/tonksparanjpe.html y en http://tonks.disted.camosun.bc.cal colloquialmet99.htm. 
La primera posición se corresponde con la de aquellos entrevistados que manifiestan que el contacto con otras culturas enriquece la propia y, además, consideran que los inmigrantes han de mantener su lengua y sus costumbres: se trata de la población favorable a un modelo basado en la integración de los inmigrantes. Luego nos encontramos con aquéllos que, aunque creen que el contacto con otras culturas enriquece la propia, piensan que los inmigrantes, una vez aquí, tendrían que olvidar su lengua y sus costumbres: es la población favorable a un modelo basado en la asimilación de los inmigrantes. La tercera posición se corresponde con la de aquéllos que creen que el contacto con otras culturas no enriquece la propia, pero que los inmigrantes han de mantener su lengua y sus costumbres; es decir, se trata de una población que rehusaría el contacto con los inmigrantes manteniendo la separación y la diferencia entre culturas: nos encontramos ante aquellos ciudadanos que prefieren un modelo basado en la separación de los grupos (y, en este caso, de los inmigrantes). $\mathrm{Y}$, finalmente, tenemos aquellos individuos que consideran que el contacto con otras culturas no enriquece y que, asimismo, los inmigrantes tendrían que olvidar su lengua y sus costumbres al instalarse aquí: se trata de una población que no sólo rehusaría el contacto, sino que también favorecería (¿obligaría?) el olvido de la lengua y las costumbres de los inmigrantes, es decir, una población favorable a la deculturación de los inmigrantes.

Además de estas cuatro posibilidades, en la muestra, nos encontramos con aquella parte de la población que ofrece una respuesta parcial en alguna de las proposiciones, o en ambas. En lugar de proceder a una imputación de respuestas, se ha preferido mantener la no-respuesta para generar una categoría de «No clasificados»: aquellos individuos de los cuales no tenemos la suficiente información como para atribuirles alguna de las actitudes arriba descritas. Dada la naturaleza de las actitudes que se analizan, es preciso evitar cualquier forma de prejuicio en su conformación, como podría ser la de asignar respuestas (por medio de técnicas y análisis estadísticos) allá donde el propio entrevistado no las ha emitido.

Así pues, con estas cinco categorías (intregacionismo, asimilacionismo, separacionismo, deculturación y sin clasificar), nuestra muestra se distribuye según se representa en el gráfico 1 .

La actitud mayoritaria es la de la población favorable a la integración de los inmigrantes, con un 52,4\% del total. Es decir que más de la mitad de la población valenciana se mostraría acorde con políticas que favorecieran el contacto entre culturas, así como el mantenimiento de la lengua y costumbres de los inmigrantes. Sin embargo, esta mayoría forma parte de un conjunto en que las categorías restantes de la población muestran algún tipo de reticencia ante ella.

Las otras tres categorías definidas presentan frecuencias bastante similares que rondan el 10\%: la deculturación, un 11,1\%; la asimilación, un 10,5\%, y la separación, un $9,1 \%$. Esto significa que cerca de un $22 \%$ de la población valenciana sería favorable a que los inmigrantes olvidaran su lengua y sus costumbres para poder instalarse aquí: la resultante de añadir los que mantienen 


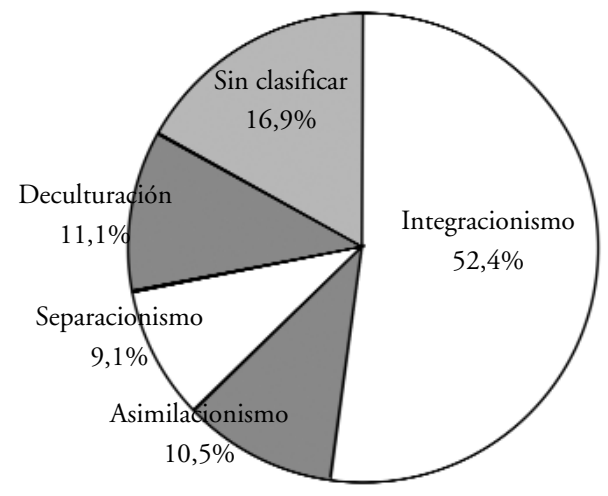

Gráfico 1. Distribución de los estilos de aculturación en la población valenciana.

Fuente: elaboración propia.

una posición asimilacionista y los favorables a la deculturación. O que un $20 \%$ de la población valenciana se mostraría favorable a una especie de "guetización» que mantuviera separadas las poblaciones inmigrantes de las autóctonas: la resultante de sumar los partidarios de la separación y de la deculturación. Todo ello sin tener en cuenta cuáles son las actitudes que se esconden detrás de aquéllos que hemos optado por no clasificar, debido a que los datos obtenidos no facilitan suficiente información para ubicarlos en este horizonte interpretativo.

En definitiva, la posición mayoritaria de la población valenciana respecto a la inmigración es la favorable a su integración y la asimilación estricta es minoritaria, en un marco en el que pueden discernirse distintas posiciones en relación con las identidades culturales convivientes.

Un contexto como éste, donde se redefinen posiciones preexistentes, no sólo es propicio para la pluralidad de posiciones, sino también para las ambigüedades y matizaciones. Con el fin de caracterizar un poco más los estilos de aculturación, se ha procedido a cruzarlos con las respuestas obtenidas en otras preguntas del cuestionario. Primero, respecto a dos cuestiones relacionadas con la percepción que tienen sobre la inmigración y los inmigrantes, y luego respecto a ciertos atributos de participación en la estructura social, que permiten esbozar sus perfiles sociales.

Este segundo nivel de análisis conduce a una valoración más matizada del integracionismo, puesto que una cuartoa parte de esta categoría considera la inmigración como negativa, y solamente un $24 \%$ de la población entrevistada ofrece un talante o un perfil actitudinal netamente integracionista y tolerante sin fisuras. Se podría decir, pues, que también el suelo más firme del integracionismo es estadísticamente reducido, y que existe un espacio de crecimiento y de afirmación potencial, que puede ser basculante desde el inte- 
gracionismo hacia otras actitudes, en función de las coyunturas históricas, dado que las convicciones se modulan en los contextos y en las situaciones concretas.

En definitiva, este análisis circunscrito de los estilos de aculturación subyacentes en una población concreta muestra que, en condiciones de pluralismo constitutivo, el asimilacionismo es minoritario; y que una mayoría, con todas las matizaciones y las ambigüedades que se quiera, se muestra favorable a la pluralidad de identidades culturales. La sociedad valenciana y la sociedad española se han adentrado durante las dos últimas décadas, y en un proceso de rápido crecimiento de la población inmigrante (tanto que Antonio Izquierdo ha hablado de «terremoto» demográfico ${ }^{10}$ ), por la senda de las sociedades etnoculturalmente plurales, y esta situación se traduce en la aparición de estilos de aculturación diversos con una tendencia favorable al integracionismo y una impugnación del asimilacionismo. Donde muchos ven un punto de llegada, una respuesta - que va del pluralismo como hecho al multiculturalismo como valor-, hay que ver, sin embargo, un espacio para el afloramiento de nuevas preguntas. De esto precisamente se ocupan las políticas de gestión de la diversidad: de observar cómo se reinventa el consenso, la cohesión y la solidaridad, en un horizonte en el que ha desaparecido el acuerdo sustantivo sobre lo que Wallerstein ha denominado el «universalismo europeo» (2008).

\section{La organización de la convivencia en un mundo plural}

Los problemas y las preguntas que flotan en la opinión pública contemporánea, cuando la diversidad se contempla esencialmente desde la realidad creciente de los flujos migratorios, tienen una índole política: cómo se pueden establecer pautas generales en medio de la relatividad de los valores y la pluralidad de universos de significado y cómo se puede producir solidaridad en medio de la eclosión y la celebración de las diferencias. ¿Es posible encontrar un núcleo básico de valores y creencias que puedan ser compartidos por personas y grupos que sostienen distintas - y muchas veces- opuestas concepciones del bien y del ideal?

Numerosos teóricos sociales y grandes organizaciones se han implicado en indagaciones y en programas destinados a buscar respuestas. El programa de UNESCO, desde hace tiempo y especialmente en los informes anuales que se han sucedido a partir de Nuestra diversidad creativa, se centra en la búsqueda de un universalismo sustantivo de mínimos (los elementos comunes a todas las culturas) ${ }^{11}$. Los resultados han sido magros, pues, como ya se ha comentado, los mismos derechos humanos son mirados con recelo y con la sospecha de ser una ideología occidentalista. El esbozo de un mapa básico de las posiciones

10. Izquierdo, 2008.

11. También cabe incluir aquí la propuesta de Diálogo de civilizaciones promovida por los gobiernos español y turco con apoyo de las Naciones Unidas. 


\begin{tabular}{|c|c|c|c|}
\hline \multirow{2}{*}{ Modelos } & \multicolumn{3}{|l|}{ Afirmaciones } \\
\hline & Cognitiva & Prospectiva & Política \\
\hline Asimilacionista & Existe la diversidad... & $\begin{array}{l}\text {... pero unas formas } \\
\text { son más valiosas que } \\
\text { otras. El modelo } \\
\text { liberal se presenta } \\
\text { como ideal. }\end{array}$ & $\begin{array}{l}\text { Política de } \\
\text { asimilación } \\
\text { individual. }\end{array}$ \\
\hline Multicultural & $\begin{array}{l}\text { Hay diferencias } \\
\text { sustantivas... }\end{array}$ & $\begin{array}{l}\text {... pero pueden ser } \\
\text { reconocidas y } \\
\text { armonizadas. }\end{array}$ & $\begin{array}{l}\text { Política de } \\
\text { reconocimiento } \\
\text { de los grupos. }\end{array}$ \\
\hline Segregador & $\begin{array}{l}\text { Hay diferencias } \\
\text { sustantivas... }\end{array}$ & $\begin{array}{l}\text {.. y no son } \\
\text { armonizables. El } \\
\text { choque es inevitable. }\end{array}$ & $\begin{array}{l}\text { Política de } \\
\text { separación } \\
\text { de los grupos. }\end{array}$ \\
\hline Pragmático & $\begin{array}{l}\text { Hay diversidad y los } \\
\text { conflictos son } \\
\text { inevitables... }\end{array}$ & $\begin{array}{l}\text {... pero también } \\
\text { puede haber } \\
\text { convivencia y } \\
\text { comunicación. }\end{array}$ & $\begin{array}{l}\text { Política de } \\
\text { mediación } \\
\text { intercultural. }\end{array}$ \\
\hline
\end{tabular}

Cuadro 2. Mapa de los modelos teóricos de aculturación.

que se dibujan en el campo intelectual puede contribuir a delimitar los escenarios que gozan de mayor viabilidad. Las sintetizaremos en cuatro modelos - asimilacionista, multicultural, segregador y pragmático- - distinguiendo las afirmaciones, cognitivas, prospectivas y propiamente políticas que los caracterizan (cuadro 2).

La posición asimilacionista sostiene que el pluralismo cultural debe subordinarse a la aceptación de los valores propios del consenso liberal en torno a los derechos individuales. Ésta es la posición, por ejemplo, de Giovanni Sartori (2003), quien identifica el multiculturalismo con el desmembramiento de la comunidad pluralista en subgrupos de comunidades cerradas y homogéneas; para él, existe una incompatibilidad radical entre pluralismo y multiculturalismo. La única garantía para una sociedad abierta radica en el pluralismo integrador, no en el multiculturalismo disgregador. Por tanto, la sociedad buena se debe asentar sobre las prácticas de asimilación de los recién llegados a los valores liberales. Pero ya hemos visto las dificultades con las que tropieza el asimilacionismo en el mundo postcolonial y de los flujos de signos. Por otra parte, este modelo tiende a reificar una definición histórica de valores y a identificarlos con los valores universales (véase la crítica de Wallerstein al universalismo europeo, 2008).

La concepción multicultural defiende la viabilidad del reconocimiento de los derechos de las diversas identidades colectivas, cada una de las cuales vive inmersa en su nicho. "Juntos, pero no revueltos», parece ser su lema. En el 
contexto canadiense y australiano, multiculturalismo hace referencia a la posibilidad de convivencia relativamente armónica y al reconocimiento de los diferentes grupos y comunidades que viven en el mismo territorio y estado (Kimlicka, 1996). Sin embargo, esta postura tiende a manejar un concepto esencialista de cultura ${ }^{12}$ y suele ignorar la relación estrecha (aunque no intrínseca) entre los procesos de diversidad cultural y los de desigualdad, dominio y jerarquización, que se dan tanto dentro de cada cultura como entre ellas. En consecuencia, los conflictos de derechos, valores e intereses son permanentes e inevitables.

Una tercera posición defiende la segregación generalizada. Parte de que el choque es inevitable; unas culturas y otras son incompatibles entre sí. La solución es el aislamiento cultural y el pacto de no agresión. Conduce al apartheid cultural. Huntington, en su famoso ensayo El choque de civilizaciones, postula una segregación generalizada de las grandes culturas, dada su incompatibilidad radical (2001). Pero no es verdad que el mundo haya sido en ningún momento un archipiélago de culturas incomunicadas, como muestra el estudio de los grandes desplazamientos de los grupos humanos y de sus pautas culturales desde la misma prehistoria. Y lo es todavía menos en el contexto de la globalización cultural. Las culturas siempre han estado en contacto y los conflictos no han conducido necesariamente y de manera regular a choques excluyentes; las dificultades de comunicación se abordan con más y mejor comunicación, no con menos, y la investigación de campo sobre la praxis multicultural de la vida rutinaria y diaria lo que muestra es la existencia de "una red elástica entrecruzada de identificaciones circunstanciales" y de identidades mutables (Baumann, 2001: 151 s.).

Los resultados de la investigación de Baumann y de tantos otros que se mueven en la observación de campo de la vida cotidiana conduce a un cierto pragmatismo. Los científicos sociales deben estudiar los contextos reales, las interacciones cotidianas, los procesos de negociación y mediación que se producen en ellos. En esos espacios opera una "conciencia multirrelacional» que, en ocasiones, utiliza el discurso de la "cultura deificada» y distintiva y, en otras, el discurso de la convergencia («todas las religiones hablan de la misma verdad»). El uso de un discurso u otro, sostiene Baumann, se basa en «criterios que son de carácter contextual y pragmático» (Baumann, 2001: 161). Ante este hecho, el pragmatismo político reconoce que la convivencia puede ser precaria y contingente, pero propugna que también se fortalece cuando se asienta sobre procedimientos regulados de arbitraje, mediación y espacios de convergencia.

Esta posición de Baumann no supone una renuncia a algún tipo de consenso y un escepticismo radicales, como los que propone John Gray (2004), sino que sitúa a la problemática en el territorio de la interacción cotidiana, que

12. Para afirmar la diferencia, se exacerban los rasgos secundarios diferenciales y se desarrollan estrategias de reforzamiento de las fronteras por parte de los grupos dominantes internos. 
es el único en el que discursos y prácticas son sometidos a la piedra de toque de la experiencia, y donde los dilemas de las encrucijadas interculturales se prueban en el experimentum crucis de las identidades híbridas y las lealtades complejas.

\section{Bibliografía}

Aierdi, Peio y Díaz De RADA, Vidal (2008). «Perfiles sociales de la opinión pública española sobre la inmigración». Revista Internacional de Sociología, núm. 50, p. $95-127$.

APPADURAI, Arjun (2001). La modernidad desbordada: Dimensiones culturales de la globalización. México: Trilce /Fondo de Cultura Económica.

ARIÑO, A. (2003). «Sociología de la cultura». En: Giner, Salvador (ed.). Teoría sociológica moderna. Barcelona: Ariel, p. 295-329.

- (dir.) (2006). Las encrucijadas de la diversidad cultural. Madrid: CIS.

Bauman, Z. (2006). Vida líquida. Barcelona: Paidós.

BAUMANN, Gerd (2001). El enigma multicultural. Un replanteamiento de las identidades nacionales, étnicas y religiosas. Barcelona: Paidós.

BERRY, J. W. (1997). «Immigration, acculturation and adaptation». Applied Psichology: An International Review, núm. 46, p. 5-68.

- (2006a). "Contexts of acculturation». En: Berry, J. W. y SAM, David L. The Cambridge handbook of acculturation psychology. Cambridge University Press, p. 27-42.

- (2006b). «Design of acculturation studies». En: BERRY, J. W. y SAM, David L. (2006). The Cambridge handbook of acculturation psychology. Cambridge University Press, p. 129-141.

BERRY, J. W. y SAM, David L. (2006). The Cambridge handbook of acculturation psychology. Cambridge University Press.

BlANCO, Cristina (2000). Las migraciones contemporáneas. Madrid: Alianza.

- (2008). «Procesos migratorios contemporáneos y su incidencia en los tradicionales paradigmas de integración». En: GARCíA ROCA, Joaquín y LACOMBA, Joan (eds.). La inmigración en la sociedad española: Una radiografía multidisciplinar. Barcelona: Edicions Bellaterra, p. 267-288.

Cuche, D. (1996). La notion de culture dans les sciences sociales. París: La Decouverte. GARCÍA ROCA, Joaquin y LACOMBA, Joan (eds.) (2008). La inmigración en la sociedad española: Una radiografía multidisciplinar. Barcelona: Edicions Bellaterra.

GraY, John (2004). Al Qaeda y lo que significa ser moderno. Barcelona: Paidós. GrUZINSKY, S. (2000). El pensamiento mestizo. Barcelona: Paidós.

Hannerz, U. (1992). Cultural complexity. Studies in the social organization of meaning. Columbia University Press.

- (1998). Conexiones trasnacionales: Cultura, gente, lugares. Madrid: Cátedra.

- (2002). ¿Choque de civilizaciones? Madrid: Tecnos (e. o. 1993).

HeLD, David y otros (1999). Global transformations. Londres: Polity Press.

Huntington, Samuel P. (2001). El choque de civilizaciones. Barcelona: Paidós (e. o. 1996).

IZQUIERDO, Antonio (2008). «Terremoto en los cimientos del modelo migratorio». En: GARCÍA ROCA, Joaquín y LACOMBA, Joan (eds.). La inmigración en la sociedad española: Una radiografia multidisciplinar. Barcelona: Edicions Bellaterra, p. 75-92. 
KimlicKA, W. (1996). Ciudadanía multicultural. Barcelona: Paidós.

LAMO DE ESPINOSA, E. (ed.) (1995). Culturas, estados, ciudadanos: Una aproximación al multiculturalismo en Europa. Madrid: Alianza.

MeTZ, Johann Baptist (2002). Dios y tiempo. Nueva teología política. Madrid: Trotta.

REDFIELD, R.; LiNTON, R. y HeRsKOVITS, M. J. (1936). «Memorandum for the study of acculturation». American Anthropologist, núm. 38, p. 149-152.

RuMmens, Joanna (Anneke). Canadian Identities: An interdisciplinary overview of Canadian research on identity. An interdisciplinary overview of Canadian research on identity. En: <http://canada.metropolis.net/events/ethnocultural/publications/ identity_e.pdf>.

SAM, L. David (2006). «Acculturation: conceptual background and core components». En: BERRY, J. W. y SAM, David L. The Cambridge handbook of acculturation psychology. Cambridge Univerity Press, p. 11-26.

SARTORI, Giovanni (2003). La sociedad multiétnica. Madrid: Taurus.

SimONS, S. E. (1901). «Social assimilation». American Journal of Sociology, núm. 6, p. $790-822$.

Tezanos, Félix (2008). «La inmigración en España». En: CAMPO, Salustiano del y TeZANOS, Félix (dirs.). España siglo XXI, 1. La sociedad. Madrid: Biblioteca Nueva, p. 93-137.

WALLERSTEIN, I. (2008). L'universalisme europeu. La retòrica del poder. València: PUV. Wellman, B. y Haythornthwaite, Caroline (2005). The Internet in everyday life. Londres: Blackwell. 